\title{
Effect of Aloe vera Gel on the Physiological, Biochemical and Quality Parameters of Pomegranate Arils cv. 'Bhagwa'
}

\author{
P. Sridevi ${ }^{1}$, V. Vijaya Bhaskar ${ }^{2^{*}}$, P. Subbaramamma ${ }^{1}$ and D.R.S. Suneetha ${ }^{1}$ \\ ${ }^{1}$ Department of Fruit Science, ${ }^{2}$ Department of Plant Physiology, Biochemistry and \\ Microbiology, College of Horticulture, Dr. Y.S.R. Horticultural University, \\ Venkataramannagudem - 534 101, West Godavari District, A.P., India \\ *Corresponding author
}

\author{
A B S T R A C T
}

\section{Keywords \\ Aloe vera gel, Antioxidant activity, Ascorbic acid, Pomegranate arils, TSS}

Article Info

Accepted:

14 December 2017

Available Online:

10 January 2018
The present study on pomegranate aril coating with Aloe vera gel at different concentrations was carried out at the Postharvest Technology Laboratory, College of Horticulture, Venkataramannagudem, West Godavari district of Andhra Pradesh during the year 2015-16. The experiment was laid out in a completely randomized design with three replications with the main objective of reducing the browning of arils by application of Aloe vera gel. Significant differences were observed among the edible Aloe vera coating treatments with regard to many of the physiological and biochemical activities of arils. The arils treated with Aloe vera gel at $30 \%$ concentration recorded significantly lowest total sugars content during the early phase of storage, whereas at later phase of storage recorded significantly highest total sugars content (14.413 and $13.692 \%$ respectively on day 12 and 16) in comparison with other concentrations. The trend with titrable acidity was also the same with Aloe vera gel at $30 \%$ concentration. Arils treated with Aloe vera gel at $30 \%$ concentration recorded significantly highest content of ascorbic acid, total anthocyanins and antioxidant activity throughout the storage period.

\section{Introduction}

Pomegranate (Punica granatum L.) popularly known as Anar belongs to the family Punicaceae. Pomegranate is considered as one of the hardiest fruit crops grown under arid subtropical and tropical conditions and found to thrive well due to its wider adaptability, resistance to drought and salinity conditions without impairing the yield and quality. The storage life of pomegranate fruit is not more than 10-15 days at room temperature.
Research efforts have helped to increase the production of pomegranate but the purpose of obtaining maximum profit will be served only if the increased production is supplemented with similar efforts to minimize the postharvest losses and enhance the shelf life. Aril is the economical part of the fruit which possess many medicinal properties and is generally sweet and acidic in taste. In the recent times, minimally processed ready-to-eat pomegranate arils have become most popular in the market. However, browning of arils is the major problem associated with quick 
spoilage of arils. Currently, there is an increasing interest in the use of Aloe vera gel in the food industry as a component of functional foods particularly in drinks, beverages and ice creams. Aloe vera gel applied as an edible coating on several fruits such as sweet cherry, table grapes and nectarines has been found effective in the retention of fruit quality by reducing the spoilage due to microbial attack. Interestingly, the anti-fungal activity of Aloe vera gel from several species has been correlated with the content of aloin, one of the major phenolic compounds of Aloe leaves. In the present study, use of Aloe vera gel at different concentrations have shown positive effect in reducing the browning and microbial spoilage of pomegranate arils thereby increasing the shelf life of arils. Keeping all these things in view, the present investigation was designed to find out the influence of Aloe vera gel in preventing or reducing the malady of browning in pomegranate arils and to find out the optimum dose or concentration of Aloe vera gel to prevent aril browning in pomegranate fruits.

\section{Materials and Methods}

The present investigation was carried out at College of Horticulture, Venkataramanna Gudem, West Godavari district of Andhra Pradesh during the year 2015-16 to elucidate the information with regard to the influence of Aloe vera gel coating on the arils of pomegranate in reducing spoilage of arils due to browning and improving the quality of pomegranate arils. The study was conducted with seven treatments viz., $\mathrm{T}_{1}$ : Pomegranate arils treated with Aloe vera gel at $15 \%$ (AVG 15), $\mathrm{T}_{2}$ : Pomegranate arils treated with Aloe vera gel at $30 \%$ (AVG 30), $\mathrm{T}_{3}$ : Pomegranate arils treated with Aloe vera gel at $45 \%$ (AVG 45), $\mathrm{T}_{4}$ : Pomegranate arils treated with Aloe vera gel at $60 \%$ (AVG 60), $\mathrm{T}_{5}$ : Pomegranate arils treated with Aloe vera gel at $75 \%$ (AVG 75), $\mathrm{T}_{6}$ : Pomegranate arils treated with Aloe vera gel at 90\% (AVG 90) and $\mathrm{T}_{7}$ : Control (no coating) with three replications in a Completely Randomized Design. Fruits of pomegranate cultivar 'Bhagwa' used in the present experiment were procured from farmer's field located at Dharmavaram village in Ananthapuram district of Andhra Pradesh. Well developed, good looking fruits with uniformity in size and maturity without any pest and disease attack were harvested and brought to the laboratory with proper packing in cardboard fibre board boxes. After unpacking, the fruits were kept overnight under open condition in the laboratory. On the next day morning, fruits were washed thoroughly under tap water and cleaned with dry cotton cloth. The arils were extracted manually after splitting the fruits with the help of sterilized knife. The entire process of aril extraction and packing were completed under total hygienic conditions in the laboratory. The spoilage was determined based on the visual observation as shrivelling of arils observed which led to fungal infection and subsequent rotting. The total soluble solids content of pomegranate arils was determined by using ERMA hand refractometer. A drop of juice obtained from arils was placed on the prism of the refractometer and observed the coincidence of shadow of sample by reading on the scale and expressed as ${ }^{\circ}$ Brix (Ranganna, 1986). The percentage of total sugars content in the pomegranate aril juice was determined by Lane and Eyon method (AOAC, 1965). Ascorbic acid content in the pomegranate arils was determined as per the procedure outlined by Ranganna (1986). Total anthocyanins content in pomegranate aril juice was determined by adopting the procedure outlined by Harborne (1973). Antioxidant activity in the pomegranate arils was assessed by using the free radical DPPH method (Bond and Michel, 1997). The data were subjected to statistical analysis as per the procedure outlined by Panse and Sukhatme (1985).

\section{Results and Discussion}


Significant differences were observed in the physiological loss in weight (PLW) of arils treated with Aloe vera gel at different concentrations (Table 1). Significantly lowest PLW was observed with Aloe vera gel at $30 \%$ concentration $(1.937,2.228,2.339$ and $2.533 \%$ respectively on day $4,8,12$ and 16 ) followed by Aloe vera gel at $15 \%$ concentration. Among the concentrations, significantly highest PLW was observed in control $(4.057,7.100,8.520$ and $11.076 \%$ respectively on day $4,8,12$ and 16) during entire period of storage at low temperature of $4^{\circ} \mathrm{C}$. The result indicated that pomegranate arils coated with Aloe vera gel at $30 \%$ concentration was found the best coating in minimizing the physiological loss in weight compared to other concentrations on all the days of observation recorded during storage at $4^{\circ} \mathrm{C}$ temperature. The aril surface coating with Aloe vera gel at $30 \%$ concentration showed a significant suppression of respiratory activity. Nanda et al., (2001) reported a weight loss up to 14 per cent after 15 days of storage in pomegranate fruits. Morillon et al., (2002) reported a reduction in the moisture loss and rate of respiration by application of Aloe vera gel coating on the arils of pomegranate. The mechanism involved in the positive effect of Aloe vera gel can be explained based on its hydrophopic property which enables formation of a barrier to water diffusion between the fruit and outside environment thus avoiding its external interference. Romero et al., (2013) reported similar observation with Aloe vera gel coating in sweet cherries and table grapes. Chauhan and Raju (2011) reported a significant reduction in the rate of respiration and a delay in reaching the peak ethylene synthesis during low temperature storage of apple cut slices coated with shellac and Aloe vera gel in combination with citric acid $(200 \mathrm{mg} / \mathrm{kg}$ ), ascorbic acid $(200 \mathrm{mg} / \mathrm{kg})$ and sodium benzoate (200 $\mathrm{mg} / \mathrm{kg}$ ).

Significant differences were observed in the spoilage per cent of arils by coating with Aloe vera gel at different concentrations and stored at a low temperature of $4^{\circ} \mathrm{C}$ (Table 1). Significantly lowest spoilage per cent of arils was observed by coating with Aloe vera gel at $30 \%$ concentration $(2.286,2.629,2.760$ and $2.989 \%$ respectively on day $4,8,12$ and 16 ) on all the days of observation recorded. Control recorded significantly highest spoilage per cent $(4.787,8.377,10.053$ and $13.069 \%$ respectively on day $4,8,12$ and 16) during entire period of storage. The result indicated that pomegranate arils coated with Aloe vera gel at $30 \%$ concentration minimized the spoilage per cent compared to other Aloe vera gel concentrations. Fruits respire even after harvest which may lead to deterioration mainly due to exhaustion of sugars. Storage life and spoilage of fruits was observed directly related to the rate of respiration (Srivastava et al., 1961). Blackening of pomegranate arils might be a physiological disorder and that the blackened arils showed increased catalytic activity compared to the normal ones (Kaulgud, 2002). Nanda et al., (2001) reported that browning of arils is a storage disorder which occurred due to storage of fruits under ambient conditions.

Significant differences were observed in the data pertaining to total soluble solids (TSS) of arils by coating with edible Aloe vera gel at different concentrations and stored at a low temperature of $4^{\circ} \mathrm{C}$ (Table 1). A gradual decrease was observed in the total soluble solids content of arils treated with different concentrations of Aloe vera gel during storage. Arils coated with edible Aloe vera gel at $30 \%$ concentration recorded significantly highest total soluble solids $(16.130,16.413,16.823$ and $15.982{ }^{\circ}$ brix respectively on day $4,8,12$ and 16). Significantly lowest TSS content was observed with control $(16.376,16.663,14.163$ and $12.889^{\circ}$ brix respectively on day $4,8,12$ and 16). The changes in TSS content of pomegranate arils coated with Aloe vera gel at 
$30 \%$ concentration was observed gradual and rhythmic when compared with other concentrations. Dang et al., (2008) observed retarded fruit ripening and improved fruit quality parameters (firmness, colour and weight loss) by postharvest application of Aloe vera $(25 \% \mathrm{w} / \mathrm{v})$ gel as a coating on nectarine fruits due to reduced rate of respiration and ethylene production which might be attributed to modification of internal atmosphere. Romero et al., (2013) observed significantly lower rate of increase in TSS content in pomegranate arils coated with Aloe vera gel and stored at low temperature. The reason might be due to delayed rate of respiration and ripening. Further, a slower rate of increase in TSS content was reported in sweet cherry and table grapes by coating with Aloe vera gel. Chauhan et al., (2014) reported significantly highest TSS content and a slower rate of ripening in green grapes treated with Aloe vera gel (5\% and $10 \%)$ in comparison to control grape berries.

Significant changes were recorded in the titrable acidity of pomegranate arils by coating with edible Aloe vera gel at different concentrations and stored at a low temperature of $4^{\circ} \mathrm{C}$ (Table 2). A gradual decrease was observed in the titrable acidity of pomegranate arils with passage of time during storage. Arils treated with Aloe vera gel at $30 \%$ concentration recorded significantly lowest titrable acidity $(0.362$ and $0.370 \%$ respectively on day 4 and 8) during the initial phase of storage, whereas, with the advancement of storage a significant increase in the titrable acidity $(0.382$ and $0.358 \%$ respectively on day 12 and 16) was observed which might be due to resumption of metabolic activities thus leading to increased conversion of organic acids to sugars when compared with other treatments. Control recorded significantly highest titrable acidity (0.369 and $0.377 \%$ respectively on day 4 and 8) during the initial phase of storage and with advancement of storage a rapid decrease in the titrable acidity
(0.306 and $0.269 \%$ respectively on day 12 and 16) was observed due to faster conversion of organic acids to sugars thereby leading to spoilage of arils.

Arils coated with Aloe vera gel led to a marginal increase in the TSS content and a minimal decrease in the titrable acidity of arils which indicate that control arils presented a more pronounced ripening development than coated arils (Mali and Grossmann, 2003). Similar kind of observation was reported earlier with starch coated strawberries and the reason was attributed to higher rate of respiration observed in the uncoated fruits. In addition, Aloe vera gel coating would have induced a modification in the internal atmosphere showing similar effect with sweet cherry fruit under modified atmosphere package conditions (Serrano et al., 2005).

Significant changes were observed in the total sugars content of pomegranate arils treated with Aloe vera gel at different concentrations and stored at a low temperature of $4^{\circ} \mathrm{C}$ (Table 2 ). Arils treated with Aloe vera gel at $30 \%$ concentration recorded significantly lowest content of total sugars (13.820 and $14.061 \%$ respectively on day 4 and 8) during the initial period of storage, whereas, significantly highest total sugars content (14.413 and $13.692 \%$ respectively on days 12 and 16) was observed during the later phase of storage. The reason might be due to a steady and slower rate of respiration observed during storage when compared with other treatments.

Control recorded significantly highest total sugars (14.030 and $14.276 \%$ respectively on day 4 and 8) during the initial period of storage, whereas, during the later part of storage a rapid decline was observed in the total sugars content (12.134 and $11.042 \%$ respectively on day 12 and 16) which might be due to rapid rate of respiration and spoilage of arils. 
Table.1 Effect of Aloe vera gel coating on physiological loss in weight, spoilage and TSS content during storage of Pomegranate arils cv. 'Bhagwa'

\begin{tabular}{|c|c|c|c|c|c|c|c|c|c|c|c|c|}
\hline \multirow[t]{2}{*}{ Treatments } & \multicolumn{4}{|c|}{ Physiological loss in weight (\%) } & \multicolumn{4}{|c|}{ Spoilage ( ${ }^{\circ}$ Brix) } & \multicolumn{4}{|c|}{ TSS $(\%)$} \\
\hline & Day 4 & Day 8 & Day 12 & Day 16 & Day 4 & Day 8 & Day 12 & Day 16 & Day 4 & Day 8 & Day 12 & Day 16 \\
\hline Aloe vera gel $15 \%$ & 2.458 & 2.925 & 3.159 & 3.459 & 2.900 & 3.451 & 3.727 & 4.081 & 16.179 & 16.463 & 16.133 & 15.327 \\
\hline Aloe vera gel $30 \%$ & 1.937 & 2.228 & 2.339 & 2.533 & 2.286 & 2.629 & 2.760 & 2.989 & 16.130 & 16.413 & 16.823 & 15.982 \\
\hline Aloe vera gel $45 \%$ & 2.744 & 4.802 & 5.762 & 7.490 & 3.237 & 5.666 & 6.799 & 8.838 & 16.212 & 16.496 & 15.671 & 14.888 \\
\hline Aloe vera gel $60 \%$ & 2.926 & 5.120 & 6.144 & 7.988 & 3.452 & 6.042 & 7.250 & 9.425 & 16.261 & 16.546 & 15.222 & 14.461 \\
\hline Aloe vera gel $75 \%$ & 3.355 & 5.871 & 7.045 & 9.158 & 3.958 & 6.927 & 8.313 & 10.806 & 16.294 & 16.579 & 14.921 & 14.175 \\
\hline Aloe vera gel $90 \%$ & 3.628 & 6.349 & 7.618 & 9.904 & 4.281 & 7.491 & 8.989 & 11.686 & 16.343 & 16.629 & 14.301 & 13.586 \\
\hline Control & 4.057 & 7.100 & 8.520 & 11.076 & 4.787 & 8.377 & 10.053 & 13.069 & 16.376 & 16.663 & 14.163 & 12.889 \\
\hline Mean & 3.015 & 4.913 & 5.798 & 7.373 & 3.557 & 5.797 & 6.841 & 8.699 & 16.257 & 16.541 & 15.319 & 14.472 \\
\hline SEm \pm & 0.048 & 0.119 & 0.152 & 0.215 & 0.057 & 0.140 & 0.180 & 0.254 & 0.006 & 0.006 & 0.015 & 0.012 \\
\hline CD at $5 \%$ & 0.148 & 0.365 & 0.469 & 0.663 & 0.175 & 0.431 & 0.554 & 0.782 & 0.018 & 0.019 & 0.046 & 0.038 \\
\hline
\end{tabular}

Table.2 Effect of Aloe vera gel coating on titrable acidity, total sugars and reducing sugars during storage of Pomegranate arils cv. 'Bhagwa'

\begin{tabular}{|c|c|c|c|c|c|c|c|c|c|c|c|c|}
\hline \multirow[t]{2}{*}{ Treatments } & \multicolumn{4}{|c|}{ Titrable acidity (\%) } & \multicolumn{4}{|c|}{ Total sugars (\%) } & \multicolumn{4}{|c|}{ Reducing sugars (\%) } \\
\hline & Day 4 & Day 8 & Day 12 & Day 16 & Day 4 & Day 8 & Day 12 & Day 16 & Day 4 & Day 8 & Day 12 & Day 16 \\
\hline Aloe vera gel $15 \%$ & 0.364 & 0.372 & 0.362 & 0.339 & 13.862 & 14.104 & 13.822 & 13.131 & 12.071 & 12.283 & 12.037 & 11.435 \\
\hline Aloe vera gel $30 \%$ & 0.362 & 0.370 & 0.382 & 0.358 & 13.820 & 14.061 & 14.413 & 13.692 & 12.038 & 12.249 & 12.555 & 11.927 \\
\hline Aloe vera gel $45 \%$ & 0.365 & 0.373 & 0.349 & 0.327 & 13.890 & 14.133 & 13.426 & 12.755 & 12.096 & 12.307 & 11.692 & 11.108 \\
\hline Aloe vera gel $60 \%$ & 0.366 & 0.374 & 0.336 & 0.314 & 13.932 & 14.176 & 13.042 & 12.389 & 12.132 & 12.345 & 11.357 & 10.789 \\
\hline Aloe vera gel $75 \%$ & 0.367 & 0.375 & 0.328 & 0.306 & 13.960 & 14.204 & 12.784 & 12.145 & 12.157 & 12.370 & 11.133 & 10.576 \\
\hline Aloe vera gel $90 \%$ & 0.368 & 0.376 & 0.310 & 0.289 & 14.002 & 14.247 & 12.252 & 11.640 & 12.194 & 12.407 & 10.670 & 10.136 \\
\hline Control & 0.369 & 0.377 & 0.306 & 0.269 & 14.030 & 14.276 & 12.134 & 11.042 & 12.218 & 12.432 & 10.567 & 9.616 \\
\hline Mean & 0.366 & 0.374 & 0.339 & 0.315 & 13.928 & 14.172 & 13.125 & 12.399 & 12.129 & 12.342 & 11.430 & 10.798 \\
\hline SEm \pm & 0.001 & 0.002 & 0.006 & 0.007 & 0.005 & 0.005 & 0.013 & 0.011 & 0.004 & 0.004 & 0.011 & 0.009 \\
\hline CD at $5 \%$ & 0.004 & 0.005 & 0.019 & 0.023 & 0.016 & 0.016 & 0.039 & 0.032 & 0.013 & 0.014 & 0.034 & 0.028 \\
\hline
\end{tabular}


Table.3 Effect of Aloe vera gel coating on ascorbic acid, total anthocyanins and antioxidant activity of Pomegranate arils cv. 'Bhagwa'

\begin{tabular}{|c|c|c|c|c|c|c|c|c|c|c|c|c|}
\hline \multirow[t]{2}{*}{ Treatments } & \multicolumn{4}{|c|}{ Ascorbic acid content (mg/100g) } & \multicolumn{4}{|c|}{ Total Anthocyanins (mg/100g) } & \multicolumn{4}{|c|}{ Antioxidant activity (\%) } \\
\hline & Day 4 & Day 8 & Day 12 & Day 16 & Day 4 & Day 8 & Day 12 & Day 16 & Day 4 & Day 8 & Day 12 & Day 16 \\
\hline Aloe vera gel $15 \%$ & 11.563 & 13.298 & 13.032 & 11.560 & 3.346 & 3.847 & 3.770 & 3.345 & 64.833 & 74.558 & 73.067 & 64.818 \\
\hline Aloe vera gel $30 \%$ & 12.045 & 13.852 & 13.575 & 12.042 & 3.453 & 3.971 & 3.892 & 3.453 & 66.925 & 76.964 & 75.424 & 66.909 \\
\hline Aloe vera gel $45 \%$ & 11.242 & 12.422 & 11.180 & 9.839 & 3.238 & 3.578 & 3.220 & 2.833 & 62.742 & 69.330 & 62.397 & 54.909 \\
\hline Aloe vera gel $60 \%$ & 10.439 & 11.535 & 10.382 & 9.136 & 3.130 & 3.458 & 3.112 & 2.739 & 60.651 & 67.019 & 60.317 & 53.079 \\
\hline Aloe vera gel $75 \%$ & 10.038 & 11.091 & 9.982 & 8.784 & 3.022 & 3.339 & 3.005 & 2.645 & 58.559 & 64.708 & 58.237 & 51.249 \\
\hline Aloe vera gel $90 \%$ & 9.315 & 10.293 & 9.264 & 8.152 & 2.914 & 3.220 & 2.898 & 2.550 & 56.468 & 62.397 & 56.157 & 49.418 \\
\hline Control & 8.030 & 7.629 & 7.018 & 6.176 & 2.698 & 2.563 & 2.358 & 2.075 & 52.285 & 49.671 & 45.697 & 40.213 \\
\hline Mean & 10.382 & 9.390 & 8.660 & 7.680 & 3.114 & 3.425 & 3.179 & 2.805 & 60.352 & 66.378 & 61.613 & 54.370 \\
\hline $\mathrm{SEm} \pm$ & 0.056 & 0.084 & 0.090 & 0.080 & 0.010 & 0.019 & 0.021 & 0.019 & 0.202 & 0.360 & 0.406 & 0.366 \\
\hline CD at $5 \%$ & 0.172 & 0.258 & 0.276 & 0.248 & 0.032 & 0.057 & 0.065 & 0.058 & 0.621 & 1.109 & 1.252 & 1.129 \\
\hline
\end{tabular}


Total sugars content of arils coated with Aloe vera gel at $30 \%$ concentration recorded a steady and slower rate of increase with passage of time up to day 12 and since then onwards decreased gradually. The trend was found the same with other treatments, but increase in the total sugars content was observed only up to day 8 and then onwards a continuous decline was observed in the total sugars content till the end of storage. Changes in the total sugars content of Aloe vera gel coated arils was found much lower even with passage of time when compared with control. The result obtained indicated that pomegranate arils coated with Aloe vera gel at $30 \%$ concentration was found the best coating in maintaining the total sugars content compared to other coatings during the entire period of storage at $4^{\circ} \mathrm{C}$ temperature. Pomegranate arils coated with Aloe vera gel at $30 \%$ concentration showed a slower rate of increase in the contents of TSS and total sugars over a period of time stored at a low temperature of $4^{\circ} \mathrm{C}$ which might be attributed to the fact that Aloe vera gel coating retarded the process of ripening and senescence hence a simultaneous delay was observed in the conversion of starch into sugars. The result of the present study was found in agreement with the earlier findings of Bishnoi et al., (2008) and Sidhu et al., (2009) in apple and soft pear respectively.

Significant differences were observed in the reducing sugars content by treating arils with Aloe vera gel at different concentrations and stored at a low temperature of $4^{\circ} \mathrm{C}$ (Table 2). Arils treated with Aloe vera gel at 30\% concentration recorded significantly lowest content of reducing sugars (12.038 and $12.249 \%$ respectively on day 4 and 8 ) during the initial period of storage, whereas, during the later phase of storage recorded significantly highest quantity of reducing sugars (12.555 and $11.927 \%$ respectively on days 12 and 16) which might be due to slower rate of respiration observed during the storage when compared with other treatments. Control recorded significantly highest content of reducing sugars (12.218 and $12.432 \%$ respectively on day 4 and 8) during the initial period of storage, whereas, at a later phase of storage a rapid decrease was observed in the reducing sugars content (10.567 and 9.616\% respectively on day 12 and 16) which might be attributed to a rapid rate of respiration thus leading to spoilage of arils. The remaining all other treatments were found intermediate between these two treatments on all the days of observation. Arils coated with Aloe vera gel at $30 \%$ concentration recorded a steady and slower rate of increase in the reducing sugars content with passage of time up to day 12 and since then onwards decreased gradually. The trend was found the same with other treatments, but the increase in reducing sugars content was observed only up to day 8 and then onwards a continuous decline in the reducing sugars content was noticed till the end of storage. Application of Aloe vera gel recorded minimal changes in the reducing sugars content with passage of time when compared with control treatment. The result obtained indicated that pomegranate arils coated with Aloe vera gel at $30 \%$ concentration maintained higher content of reducing sugars when compared with all other treatments on all the days of storage at $4^{\circ} \mathrm{C}$ temperature.

Significant differences were observed in the ascorbic acid content of pomegranate arils treated with Aloe vera gel at different concentrations and stored at a low temperature of $4^{\circ} \mathrm{C}$ (Table 3). A gradual decrease was observed in the ascorbic acid content of pomegranate arils with passage of time during storage. Significantly highest ascorbic acid content was observed in arils coated with Aloe vera gel at 30\% concentration $(12.045,13.852,13.575$ and $12.042 \mathrm{mg} / 100 \mathrm{~g}$ respectively on day $4,8,12$ and 16) followed by Aloe vera gel at $15 \%$ concentration during all the days of 
observation. Control recorded significantly lowest content of ascorbic acid (8.030, 7.629, 7.018 and $6.176 \mathrm{mg} / 100 \mathrm{~g}$ respectively on day 4, 8, 12 and 16). A gradual and steady increase was observed in the ascorbic acid content of arils by application of Aloe vera gel at $30 \%$ concentration up to day 12 and since then onwards a gradual decrease was observed. The trend was found the same with other treatments, but the increase in the content of ascorbic acid was only up to day 8 and then onwards a continuous decline was observed till the end of storage period. The result has indicated that application of Aloe vera gel at $30 \%$ has maintained significantly higher amounts of ascorbic acid compared to other treatments during storage. Certainly the value of ascorbic acid content of pomegranate arils was found to be higher than that of untreated arils. Similar kind of result was reported earlier in papaya fruits which were treated with Aloe vera gel as a biopreservative $(86.55 \mathrm{mg}$ ) than the control fruits (61.10 $\mathrm{mg}$ ) during storage at a temperature range of $25-29^{\circ} \mathrm{C}$ with $82-84 \% \mathrm{RH}$ (Brishti et al., 2013). The reason might be due to lower permeability of oxygen by coating with Aloe vera gel which delayed the deteriorative oxidation reaction of ascorbic acid content (Srinu et al., 2012). Zhou et al., (2008) reported a reduction in the rate of respiration by application of Aloe vera gel thereby a delay was noticed in the decline of vitamin $\mathrm{C}$ content of pear fruits during storage. Rasp berries coated with Aloe vera gel showed an increase in the ascorbic acid levels throughout the storage period. Further, coating with $A$. vera gel was found more effective in the retention of ascorbic acid content because of the lowest gas permeability that inhibited the respiration rate and retarded the overall ascorbic acid content.

Significant differences were observed in the anthocyanins content of pomegranate arils by application of Aloe vera gel at different concentrations and stored at a low temperature of $4^{\circ} \mathrm{C}$ (Table 3). A gradual decrease was observed in the total anthocyanins content with passage of time by treating with different concentrations of Aloe vera gel. Significantly highest total anthocyanins content was recorded in arils treated with Aloe vera gel at $30 \%$ concentration $(3.453,3.971,3.892$ and 3.453 $\mathrm{mg} / 100 \mathrm{~g}$ respectively on day $4,8,12$ and 16) followed by Aloe vera gel at $15 \%$ concentration on all the days of observation recorded. Control recorded significantly lowest content of total anthocyanins (2.698, $2.563,2.358$ and $2.075 \mathrm{mg} / 100 \mathrm{~g}$ respectively on day 4, 8, 12 and 16) on all the days of observation. Arils treated with Aloe vera gel at $30 \%$ concentration recorded a steady and slower rate of increase in the total anthocyanins content with passage of time up to day 12 and since then onwards a gradual decrease was observed. Trend was found the same with other treatments, but increase in the content of total anthocyanins was only up to day 8 and then onwards a decline was observed in the total anthocyanins content till the end of storage. The changes in total anthocyanins content by application of Aloe vera gel at $30 \%$ concentration was found much less even with passage of time during storage. Similar kind of result was observed in sweet cherries by dipping in Aloe vera gel immediately after harvesting (Romero et al., 2013).

The changes in the antioxidant activity of pomegranate arils was found significant by application of Aloe vera gel at different concentrations and stored at a low temperature of $4^{\circ} \mathrm{C}$ (Table 3). The antioxidant activity of pomegranate arils was found decreased gradually by application of Aloe vera gel with passage of time during storage. Significantly highest antioxidant activity of pomegranate arils was recorded in arils coated with Aloe vera gel at $30 \%$ concentration (66.925, 76.964, 75.424 and 66.909\% respectively on day $4,8,12$ and 16) followed 
by Aloe vera gel at $15 \%$ concentration during the storage. Control recorded significantly lowest antioxidant activity (52.285, 49.671, 45.697 and $40.213 \%$ respectively on day 4,8 , 12 and 16) on all the days of observation recorded. Application of Aloe vera gel at 30\% concentration recorded a steady and slower rate of increase in the antioxidant activity during storage up to day 12 and since then onwards decreased gradually. The trend was found the same with other treatments, but increase in the antioxidant activity was found only up to day 8 and then onwards a continuous decline was observed in the antioxidant activity of arils till the end of storage. The changes observed in the antioxidant activity of pomegranate arils treated with Aloe vera gel at $30 \%$ concentration was found much less even with passage of time when compared with other treatments. In the present study, antioxidant activity of arils was found increased by treating with different concentrations of Aloe vera gel. Significantly highest antioxidant activity was observed by treating with $30 \%$ concentration followed by $15 \%$ concentration of Aloe vera gel. Pomegranate is a rich source of natural antioxidants which includes phenolic compounds and anthocyanins. Hassanpour (2015) observed that rasp berries coated with Aloe vera gel recorded a higher antioxidant activity and total anthocyanins content than those of control (non-treated). The treated fruits exhibited lower incidence of decay during storage at $4^{\circ} \mathrm{C}$ than the control group. Serrano et al., (2006) observed an increase in the antioxidant activity of grapes treated with Aloe vera gel. Further, Hu et al., (2005) reported that Aloe vera gel might have increased the resistance of tissues to decay by enhancing antioxidant activity thereby free radical scavenging capability. A large number of compounds have been reported in the composition of Aloe vera gel (Ni et al., 2004) but it is thought that aloe-emodin is one of the main components which contribute to the antioxidant activity. Presence of higher quantities of phenolics and anthocyanins in Aloe vera gel might have attributed to the better maintenance of aril quality (Serrano et al., 2006). The present result was found in agreement with the above findings.

\section{References}

A.O.A.C. 1965. Association of Official Analytical Chemists - Official methods of Analysis, Washington, D.C.

Bishnoi, A., Chawla, H.M., Rani, G., Saxena, R. and Sreenivas, V. 2008. Effect of formulation derived from terpenoidal oligomer on shelf-life of apples without refrigeration. Journal of Food Science and Technology. 45: 412-15.

Bond, S. and Michel, R. 1997. Antioxidant activity analysis in various fruit crops, Journal of Postharvest Biology and Technology. 52: 654-58.

Brishti, F.H., Misir, J. and Sarker, A. 2013. Effect of bio-preservatives on storage life of papaya fruit (Carica Papaya L.). International Journal of Food Studies. 2(1): 126-36.

Chauhan, O. P. and Raju, P.S. 2011.Shellac and aloe-gel-based surface coatings for maintaining keeping quality of apple slices. Journal of Food Chemistry. 126: 961-66.

Chauhan, S., Gupta, K.C. and Agrawal, M. 2014.Application of biodegradable Aloe vera gel to control postharvest decay and longer the shelf life of Grapes. International Journal of Microbiology and Applied Sciences. 3(3): 632-42.

Dang, K.T.H., Singh, Z. and Swinny, E.E. 2008. Edible coatings influence fruit ripening, quality and aroma biosynthesis in mango fruit. Journal of Agriculture and Food Chemistry. 56, 1361-70.

Harborne, J.B. 1973. Phytochemical methods. Chapman and Hall International Ed. Toppan Co. Ltd., Tokyo, Japan.

Hassanpour, H. 2015. Effect of Aloe vera gel coating on antioxidant capacity, antioxidant enzyme activities and decay in raspberry fruit. Journal of Food Science and Technology. 60: 495-501. 
$\mathrm{Hu}$, Q., Hu, Y. and $\mathrm{Xu}$, J. 2005. Free radicalscavenging activity of Aloe vera (Aloe barbadensis Mill) extracts by supercritical carbon dioxide extraction. Food Chemistry. 31: $90-91$.

Kaulgud, S.N. 2002. Pomegranate aril blackening: Fungal or physiological disorder advances in arid and semi-arid fruit crops. Center of Advanced Studies in Horticulture (Fruits), MPKV, Rahuri, Maharashtra.

Mali, S. and Grossmann, M.V.E. 2003. Effects of yam starch on storability and quality of fresh strawberries (Fragaria ananassa). Journal of Agriculture and Food Chemistry. 21:7005-11.

Morillon, V., Debeaufort, F., Blond, G., Capelle, M. and Voilley, A. 2002. Factors affecting the moisture permeability of lipid-based edible films: A Review. Food Science and Nutrition. 42: 67-89.

Nanda, S., Rao, D.V.S. and Krishnamurthy, S. 2001. Effects of shrink film wrapping and storage temperature on the shelf life and quality of pomegranate fruits cv. Ganesh. Journal of Postharvest Biology and Technology. 22(1): 61-69.

Ni, Y., Turner, D., Yates, K.M. and Tizard, I. 2004. Isolation and characterization of structural components of Aloe vera $\mathrm{L}$. leaf pulp. Journal of International Immuno Pharmacology, 4:1745-55.

Panse, V.G. and Sukhtame, P.V. 1985. Statistical methods for agricultural workers. Indian Council of Agricultural Research, New Delhi.

Ranganna, S. 1986. Hand book of analysis and quality control for fruits and vegetable products. Tata McGraw Hill Publishing Company Limited, New Delhi.

Romero, D.M., Castillo, S., Guillena, F., Huertas,
M., Mulaa, D., Pedro, J., Zapata, P.J. and Serrano, M. 2013. Aloe vera gel coating maintains quality and safety of ready-to-eat pomegranate arils. Postharvest Biology and Technology. 86: 107-12.

Serrano, M., Romero, D., Castillo, S., Valero, D. 2005. Chemical constituents and antioxidant activity of sweet cherry at different ripening stages. Journal of Agriculture and Food Chemistry. 53: 274145.

Serrano, M., Valverde, J.M., Guillén, F., Castillo, S., Romero, D.M., Valero, D. 2006. Use of Aloe vera gel coating preserves the functional properties of table grapes. Journal of Agriculture and Food Chemistry. 54: 3882-86.

Sidhu, G.S., Dhillon, W.S. and Mahajan, B.V.C. 2009. Effect of waxing and packaging on storage of pear cv. Punjab Beauty. Indian Journal of Horticulture. 66: 239-44.

Srinu, B., Vikram, K.B., Rao, L.V., Kalakumar, B., Rao, T.M. and Reddy, A.G. 2012. Screening of antimicrobial activity of Withania somnifera and Aloe vera plant extracts against food borne pathogens. Journal of Chemical and Pharmaceutical Research. 4(11): 4800-03.

Srivastava, H.C, Dalal, V.B. and Subramanyam, H. 1961.Wax emulsion for successful storage and transportation of perishables. Circular. No. 40 CFTRI, Mysore.

Zhou, R., Mo, Y., Li, Y., Zhou, Y., Zhang, G. and $\mathrm{Hu}, \quad$ Y. 2008. Quality and internal characteristics of Huanha pears (Pyrus pyrifolia Nakai, cv. Huanhua) treated with different kinds of coating during storage. Journal of Postharvest Biology and Technology. 40: 171-79.

\section{How to cite this article:}

Sridevi, P., V. Vijaya Bhaskar, P. Subbaramamma and Suneetha, D.R.S. 2018. Effect of Aloe vera Gel on the Physiological, Biochemical and Quality Parameters of Pomegranate Arils cv. 'Bhagwa'. Int.J.Curr.Microbiol.App.Sci. 7(01): 1757-1766. doi: https://doi.org/10.20546/ijcmas.2018.701.213 